\title{
Relativistic calculations on E1 transitions in As-like ions
}

\author{
E. Charro and I. Martín \\ Departamento de Química Física, Universidad de Valladolid, 47011 Valladolid, Spain
}

Received October 21, 1997; accepted March 18, 1998

\begin{abstract}
Relativistic Quantum defect Orbital (RQDO) and Multiconfiguration Dirac-Fock (MCDF) calculations of oscillator strengths for the $4 \mathrm{p}^{3}-4 \mathrm{p}^{2} 5$ s transition array of the Br III-La XXV As-like ions have been performed. For most of the studied ions and transitions no previous data have been found in the literature.
\end{abstract}

Key words: atomic data - atomic processes

\section{Introduction}

The physics of highly ionized atoms is not only a field of extraordinary richness in specific physical phenomena, but also a part of atomic physics that cross-correlates with many other scientific disciplines such as astrophysics, plasma physics, heavy ion physics, etc. Apart from its pure scientific importance, the physics of highly charged ions also has strong impact on research in several applied physics and technological areas (for example in fusion research and materials science) which provides a further stimulus for the development of this field.

One of the properties of highly ionized atoms that is a subject of considerable interest for many fields, such astrophysics and fusion plasma research, is the transition probability between different electronic levels and, more specifically, the oscillator strength.

For many years we have applied the Quantum Defect Orbital method, both in its non-relativistic (QDO) (Simons 1974) and its relativistic (RQDO) (Martín \& Karwowski 1991) versions, to the calculation of oscillator strengths and photoionization cross sections of a rather large number of atomic species, including several isoelectronic sequences (see, e.g. Charro et al. 1996, 1997).

One of the isoelectronic series of which the heavier species have not been so far studied, to our knowledge, is that of the arsenic atom. As I has itself been the object of great interest in the last few years (see e.g. Bengston et al. 1992), given the detection of its
$4 \mathrm{p}^{2} 5 \mathrm{~s}{ }^{4} \mathrm{P}_{3 / 2}-4 \mathrm{p}^{3}{ }^{4} \mathrm{~S}_{3 / 2}^{\mathrm{o}}$ line in the spectrum of Chi Lupi, a HgMn type of star, through a spectrometer on board the Hubble Space Telescope. Other atomic systems that have been found to exist in different ionization degrees in Chi Lupi are Sr, Y, Zr, Ru and Pd (Leckrone et al. 1996), which are potentially members of the As I isoelectronic sequence, although there are so far no reports on the existence of these elements in As-like form.

For the reasons described above, we have undertaken the study of the intensities of all the allowed lines of $4 \mathrm{p}^{3}-4 \mathrm{p}^{2} 5 \mathrm{~s}$ transition array in a number of As-like ions ranging from $\operatorname{BrIII}(Z=35)$ to $\operatorname{LaXXV}(Z=57)$. Two methodologies have been followed: the aforementioned RQDO method and the multiconfiguration DiracFock (MCDF) formalism with the GRASP code written by Grant et al. $(1980,1989)$.

\section{Computational procedures}

\subsection{Relativistic quantum defect orbital method}

The RQDO method has been described in detail (Martín \& Karwowski 1991). We shall thus only mention here those aspects of the formalism which are relevant to this study.

The relativistic quantum defect orbitals are the analytical solutions of a quasi relativistic second-order Diraclike equation with a model Hamiltonian that contains the quantum defect as a parameter. This model Hamiltonian allows for an effective variation of the screening effects with the radial distance and, as a consequence, the radial solutions behave approximately correctly in the core region of space, and display a correct behaviour at large radial distances. These have been found to be, in many cases, the most relevant regions contributing to the transition integral. The RQDO's lead to closed-form analytical expressions for the transition integrals, which allows us to calculate transition probabilities with simple algebra and little computational effort.

The RQDO Hamiltonian accounts for core-valence polarization only implicitly, through the inclusion of the 
Table 1. Experimental energy levels for some As-like ions, in $\mathrm{cm}^{-1}$

\begin{tabular}{|c|c|c|c|c|c|c|c|}
\hline ION & $\mathrm{Br} \mathrm{III}^{\mathrm{a}}$ & $\mathrm{Rb} \mathrm{V}^{\mathrm{b}}$ & $\mathrm{Sr} \mathrm{VI}^{\mathrm{b}}$ & $\mathrm{Y} \mathrm{VII}^{\mathrm{c}}$ & $\mathrm{Zr} \mathrm{VIII}{ }^{\mathrm{c}}$ & $\mathrm{Nb} \mathrm{IX}^{\mathrm{c}}$ & Mo $\mathrm{X}^{\mathrm{c}}$ \\
\hline \multicolumn{8}{|c|}{$4 s^{2} 4 p^{3}$} \\
\hline${ }^{2} \mathrm{D}_{3 / 2}^{\mathrm{o}}$ & 15042 . & & & 21611. & 23156 . & 24881. & 26886 . \\
\hline${ }^{2} \mathrm{D}_{5 / 2}^{\mathrm{o}}$ & 16301. & & & 26121. & 28930 . & 32026 . & 35522 . \\
\hline${ }^{2} \mathrm{P}_{1 / 2}^{\mathrm{o}}$ & 26915. & & & 42364 . & 46381. & 50672 . & 55313. \\
\hline${ }^{2} \mathrm{P}_{3 / 2}^{\mathrm{o}}$ & 28579 . & & & 49289. & 55605 . & 62632 . & 70544 . \\
\hline \multicolumn{8}{|c|}{$4 s^{2} 4 p^{2} 5 s$} \\
\hline${ }^{4} \mathrm{P}_{1 / 2}$ & 145417. & & 327320 . & 398054 . & 473532 . & 553867. & 638999. \\
\hline${ }^{4} \mathrm{P}_{3 / 2}$ & 147670. & 266420 . & 333260 . & 405878 . & 483622 . & 566634 & 654947. \\
\hline${ }^{4} \mathrm{P}_{5 / 2}$ & 150260. & 270710 & 338650 . & 412177. & 490913. & 574934 & 664258 \\
\hline${ }^{2} \mathrm{P}_{1 / 2}$ & 149200. & 268680 & 338240 . & 411076 & 489084 & 572400 & 660981. \\
\hline${ }^{2} \mathrm{P}_{3 / 2}$ & 152110. & 271790 . & 343870 . & 417527 . & 496387. & 580533. & 669948. \\
\hline${ }^{2} \mathrm{D}_{5 / 2}$ & 157747. & 285920 . & 355820 . & 431523. & 512828. & 599844. & 692660. \\
\hline${ }^{2} \mathrm{D}_{3 / 2}$ & 158512. & 286790 . & 356820 . & 432898 . & 514585. & 602011. & 695263. \\
\hline${ }^{2} \mathrm{~S}_{1 / 2}$ & & 307080. & 378990. & 456682. & 539792. & 628560 . & 723115 . \\
\hline
\end{tabular}
a) Compilation by Kelly (1987).
b) Observed by O'Sullivan (1989) for RbV and by O'Sullivan
\& Maher (1989) for SrVII, see text.
c) Measurements by Reader \& Acquista (1981), see text.

quantum defect. However, it is our experience that the explicit inclusion of the above effect is often important. As in some previous works (see, e.g., Charro et al. 1996, 1997 ) we have performed two types of RQDO $f$-value calculations: one with the standard dipole-length transition operator, $Q(r)=r$, and other with a core-polarization corrected form of the former (Bielińska-Wạz 1992):

$Q(r)=r\left[1-\frac{\alpha}{r^{3}}\left[1-\exp \left(-r / r_{\mathrm{c}}\right)\right]^{3}\right]$,

where $\alpha$ is the core polarizability and $r_{\mathrm{c}}$ is a cut-off radius, chosen to be in these calculations the mean radius of the outermost orbital of the core, calculated in accord with an expression given by Chichkov \& Shevelko (1981). The core has been considered in all the cases to be $\mathrm{Ar} 3 \mathrm{~d}^{10} 4 \mathrm{~s}^{2}$. For the core polarizabilities we have taken the values supplied by Fraga et al. (1976), which do not go beyond Nb IX $(Z=41)$. For the higher ions in the sequence we have found the core polarizabilities in atomic units from the following expression

$\ln \alpha=38.838-10.615 \ln Z$,

which has been obtained through a fitting of the $\alpha$-values of Fraga et al. (1976) from As I $(Z=33)$ to Nb IX ( $Z=$ 41 , with a correlation factor of 0.9967 . $Z$ is the atomic number. The values of the core polarizabilities and cut-off radii, in atomic units, are shown in graph form in Fig. 1.

In the RQDO context, energy level data are required in order to obtain the quantum defects. For BrIII we have employed the data provided by a compilation by Kelly (1987). For the quadruplet levels of the $4 \mathrm{p}^{2} 5 \mathrm{~s}$ configuration we have taken the observed energy values of O'Sullivan (1989) for Rb V and O'Sullivan \& Maher (1989) for Sr VI. In both cases, the corresponding spectra of laser- produced plasmas were recorded, and the position of the lines was identified from MCDF calculations, which were also employed to determine $f$-values. These authors (O'Sullivan 1989; O'Sullivan \& Maher 1989) report that the agreement between the calculated and observed energies is generally quite good. For the ions Y VII to Mo X we have used experimental energies by Reader \& Acquista (1981). Early energy data measured by Rahimullah et al. (1976) for these ions are in good agreement with those of Reader \& Acquista (1981). The energies of the levels of the ground and excited configurations up to Mo X that we have used in our RQDO calculations, for which some experimental data are available, are collected in Table 1.

All the above data have relied on theoretical predictions and observed intensities for an identification of the lines, as well as an analysis of the systematic trends complied by the level energies along the isoelectronic sequence (O'Sullivan 1989; O'Sullivan \& Maher 1989; Reader \& Acquista 1981; Rahimullah et al. 1976). Reader \& Acquista (1981) employ Hartree-Fock (HF) calculations. These authors estimate uncertainties to range from $0.6 \mathrm{~cm}^{-1}$ to $15 \mathrm{~cm}^{-1}$ for the levels of the $4 \mathrm{p}^{3}$ and $4 \mathrm{p}^{2}$ 5s configurations, the uncertainties increasing from the ground to the excited configurations, and also from $\mathrm{Y}$ VII to Mo X.

In Tables 2 to 4 we display the theoretical energies obtained in the present work with the MCDF approach and employed in our MCDF calculations of oscillator strengths. In Tables 1 to 3 the energy of the lowest level 
Table 2. MCDF energy levels for some As-like ions, in $\mathrm{cm}^{-1}$

\begin{tabular}{|c|c|c|c|c|c|}
\hline ION & $\mathrm{Rb} \mathrm{V}$ & Sr VI & Y VII Zr VIII & $\mathrm{Nb}$ IX & Mo X \\
\hline \multicolumn{6}{|l|}{$4 s^{2} 4 p^{3}$} \\
\hline${ }^{2} \mathrm{D}_{3 / 2}$ & 23282. & 24803. & 26266. 27756. & 29371. & 31220. \\
\hline${ }^{2} \mathrm{D}_{5 / 2}$ & 26091. & 28684 . & 31396. 34297. & 37461. & 40968. \\
\hline${ }^{2} \mathrm{P}_{1 / 2}$ & 37061. & 40809. & 44649. 48659. & 52917. & 57507. \\
\hline${ }^{2} \mathrm{P}_{3 / 2}$ & 40694 . & 46013. & 51794. 58151. & 65203 & 73073. \\
\hline \multicolumn{6}{|c|}{$4 s^{2} 4 p^{2} 5 s$} \\
\hline${ }^{4} \mathrm{P}_{1 / 2}$ & \multicolumn{5}{|c|}{279262.328485 .3} \\
\hline${ }^{4} \mathrm{P}_{3 / 2}$ & \multicolumn{5}{|c|}{ 282543. 334076. 406808 } \\
\hline${ }^{4} \mathrm{P}_{5 / 2}$ & \multicolumn{5}{|c|}{ 290176. 337474. 413651. 492779. 577159. 666802.} \\
\hline${ }^{2} \mathrm{P}_{1 / 2}$ & \multicolumn{5}{|c|}{ 285607. 341072. 414078. 492407. 575954. 664736.} \\
\hline${ }^{2} \mathrm{P}_{3 / 2}$ & \multicolumn{5}{|c|}{ 290973. 347223. 421276. 500626. 585178. 674945.} \\
\hline $\mathrm{D}_{5 / 2}$ & \multicolumn{5}{|c|}{ 293253. 360449. 436428. 518007. 605224. 698158.} \\
\hline${ }^{2} \mathrm{D}_{3 / 2}$ & \multicolumn{5}{|c|}{ 293637. 361481. 437855. 519893. 607621. 701105.} \\
\hline${ }^{2} \mathrm{~S}_{1 / 2}$ & \multicolumn{5}{|c|}{ 316082. 388487. 466569. 550209. 639446. 734356.} \\
\hline
\end{tabular}

Table 3. Doublet MCDF energy levels for the $4 \mathrm{p}^{3}$ configuration, in $\mathrm{cm}^{-1}$

\begin{tabular}{|lrrrr|}
\hline & & & & \\
ION & ${ }^{2} \mathrm{D}_{3 / 2}^{\circ}$ & ${ }^{2} \mathrm{D}_{5 / 2}^{\circ}$ & ${ }^{2} \mathrm{P}_{1 / 2}^{\mathrm{o}}$ & ${ }^{2} \mathrm{P}_{3 / 2}^{\mathrm{o}}$ \\
\hline Ru XII & 36099. & 49345. & 68032. & 91783. \\
Rh XIII & 39371. & 54384. & 74140. & 102884. \\
Pd XIV & 43346. & 60098. & 80922. & 115320. \\
Ag XV & 48116. & 66558. & 88450. & 129214. \\
Cd XVI & 53761. & 73831. & 96792. & 144683. \\
In XVII & 60349. & 81977. & 106010. & 161841. \\
Sn XVIII & 67935. & 91053. & 116160. & 180801. \\
Sb XIX & 76572. & 101113. & 127299. & 201674. \\
Te XX & 86311. & 112213. & 139482. & 224575. \\
I XXI & 97201. & 124409. & 152766. & 249624. \\
Xe XXII & 109296. & 137759. & 167209. & 276943. \\
Cs XXIII & 122651. & 152326. & 182875. & 306661. \\
Ba XXIV & 137325. & 168173. & 199827. & 338912. \\
La XXV & 153380. & 185369. & 218133. & 373835. \\
\hline
\end{tabular}

of the ground configuration, ${ }^{4} \mathrm{~S}_{3 / 2}^{\mathrm{o}}$, which is equal to zero in $\mathrm{cm}^{-1}$, has been omitted. The comparison of our MCDF energies, as reported in Table 2, with the data by other authors (Table 1) makes us confident as to their accuracy.

In order to have a basis to test the quality of the energies employed, we have plotted the energies of the ground and excited configurations in Figs. 2 and 3, respectively. They present a regular behaviour, in all cases, along the isoelectronic sequence, and the connection between the present MCDF and the experimental energies (Reader \& Acquista 1981) is smooth.

Other input data that are also needed in the RQDO calculations were the ionization energies of the atomic systems. The corresponding values from As I to Kr IV are supplied by Kelly (1987) and a few more by Fraga et al.
Table 4. MCDF energy levels for the $4 \mathrm{p}^{2} 5 \mathrm{~s}$ configuration, in $\mathrm{cm}^{-1}$

\begin{tabular}{|c|c|c|c|c|c|}
\hline ION & ${ }^{4} \mathrm{P}_{1 / 2}$ & ${ }^{4} \mathrm{P}_{3 / 2}$ & ${ }^{4} \mathrm{P}_{5 / 2}$ & ${ }^{2} \mathrm{P}_{1 / 2}$ & ${ }^{2} \mathrm{P}_{3 / 2}$ \\
\hline Ru XII & . & 049210 & 002001. & 858189. & 870295 . \\
\hline $\mathrm{Rh}$ XIII & 926275 . & 953680. & 967637. & 962964. & 975982 . \\
\hline Pd XIV & 1030771. & 1063577. & 1078688. & 1073174. & 1087080. \\
\hline Ag XV & 1140020 . & 1178954 . & 1195196. & 1188863. & 1203634 . \\
\hline Cd XVI & 1254007. & 1299849. & 1317147. & 1310071. & 1325687. \\
\hline In XVII & 1372712 . & 1426294. & 1444725 . & 1436833. & 1453274 . \\
\hline Sn XVIII & 1496108 . & 1558319 . & 1577811. & 1569178. & 1586426 . \\
\hline $\mathrm{Sb}$ XIX & 1624167. & 1695954. & 1716485 . & 1707136 . & 1725175 . \\
\hline Te XX & 1756857 . & 1839227. & 1860777. & 1850735. & 1869552. \\
\hline I XXI & 1894148. & 1988167. & 2010718. & 2000006. & 2019585. \\
\hline Xe XXII & 2036007. & 2142807 . & 2166341. & 2154980 . & 2175310 . \\
\hline Cs XXIII & 2182400 & 2303179 . & 2327682 . & 2315690 . & 2336761 \\
\hline $\mathrm{Ba}$ XXIV & 2333297. & 2469321. & 2482173 . & 2494777 . & 2503974 . \\
\hline La XXV & 2488663. & 2641271. & & 2654466 . & 2676989 . \\
\hline
\end{tabular}

Table 4. continued

\begin{tabular}{|lrrr|}
\hline ION & ${ }^{2} \mathrm{D}_{5 / 2}$ & ${ }^{2} \mathrm{D}_{3 / 2}$ & ${ }^{2} \mathrm{~S}_{1 / 2}$ \\
\hline Ru XII & 901566. & 905676. & 941583. \\
Rh XIII & 1012246. & 1016950. & 1054107. \\
Pd XIV & 1129044. & 1134341. & 1172710. \\
Ag XV & 1252057. & 1257940. & 1297490. \\
Cd XVI & 1381373. & 1387834. & 1428542. \\
In XVII & 1517080. & 1524109. & 1565957. \\
Sn XVIII & 1659262. & 1666848. & 1709822. \\
Sb XIX & 1808005. & 1816137. & 1860227. \\
Te XX & 1963394. & 1972062. & 2017261. \\
I XXI & 2125520. & 2134715. & 2181018. \\
Xe XXII & 2294478. & 2304191. & 2351596. \\
Cs XXIII & 2470367. & 2480590. & 2529096. \\
Ba XXIV & 2653293. & 2664017. & 2713625. \\
La XXV & 2843364. & 2854584. & 2905293. \\
\hline
\end{tabular}

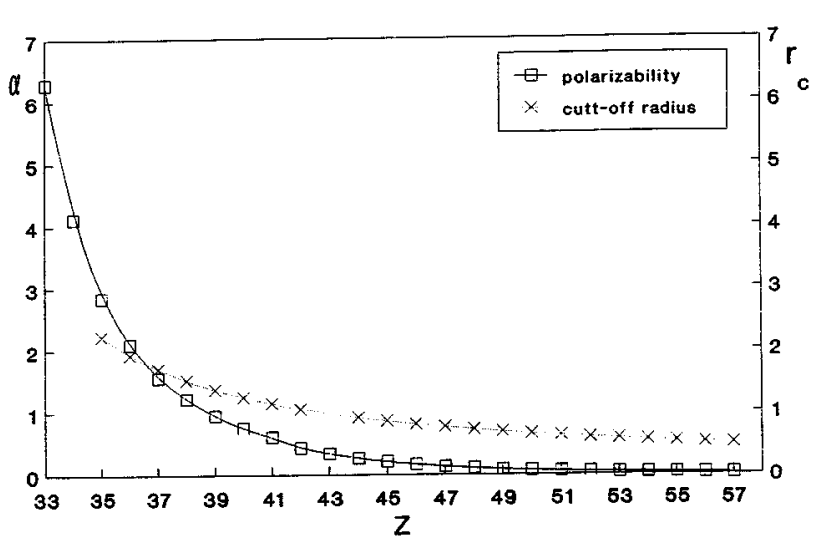

Fig. 1. Core dipole polarizabilities and cut-off radii, in atomic units, for As-like ions 


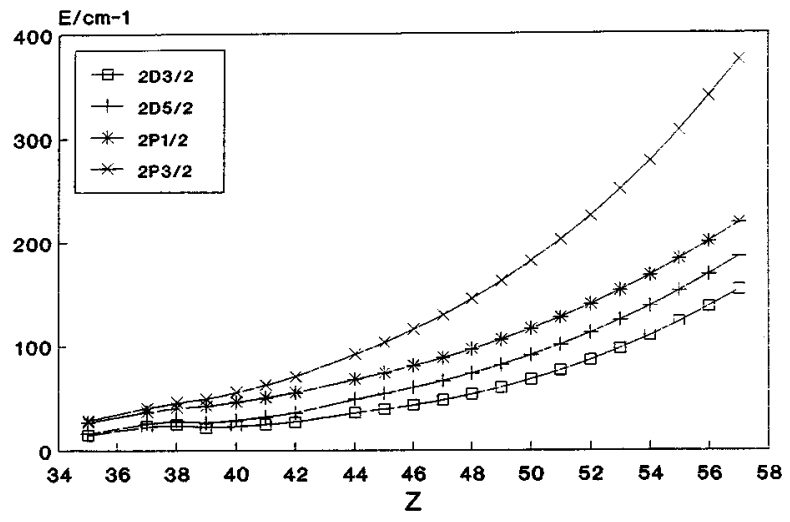

Fig. 2. Energies for the doublet levels of the ground configuration, $4 \mathrm{p}^{3}$, taken from Tables 1 and 2, in As-like ions versus the atomic number

(1976). For the few remaining ions for which $f$-values are reported we have employed an extrapolation formula obtained by fitting the ionization energies in $\mathrm{cm}^{-1}$ of the previous ions. This formula is the following

$E_{i}=86.96 Z^{3}-2806.66 Z^{2}$,

where, again, $Z$ is the atomic number. The correlation factor was 0.9998 .

\subsection{Multiconfiguration Dirac-Fock method}

The MCDF method, as implemented in the GRASP code (Grant 1989), is a generalization of the Dirac-Fock formalism. It employs a multiconfigurational trial function in the variation of the total energy. Within this model, an atomic state function is represented as a linear combination of configuration state functions built from antisymetrized products of standard Dirac orbitals. These orbitals are eigenfunctions of the one-electron total angular momentum operator, rather than of the spin and orbital momentum operators independently (as it is the case in the non-relativistic multiconfigurational HartreeFock method). For details of the atomic MCDF model we refer to a review by Grant (Grant 1988).

The extended average level (EAL) mode with the Breit and QED corrections (Grant 1988) has been employed. The following configurations have been introduced:

$4 \mathrm{p}^{3}+4 \mathrm{p}^{5}$ to describe the ground configuration.

$4 \mathrm{p}^{2} 5 \mathrm{~s}+4 \mathrm{~s} 4 \mathrm{p}^{4}+4 \mathrm{p}^{2} 4 \mathrm{~d}$ to describe the excited configuration.

The choice of these configurations has been made on the grounds of the comments by Bieron \& Migdalek (1980) and O'Sullivan (1989) and by observing that this configuration mixing leads to a good accord between dipolelength (Babushkin gauge) and dipole velocity (Coulomb gauge) MCDF oscillator strengths for most of the transitions studied. Other configurations such as $4 \mathrm{~s} 4 \mathrm{p}^{3} 4 \mathrm{~d}$ and $4 \mathrm{p}^{2} 5 \mathrm{p}+4 \mathrm{p}^{2} 5 \mathrm{~d}$ for the ground and excited states,

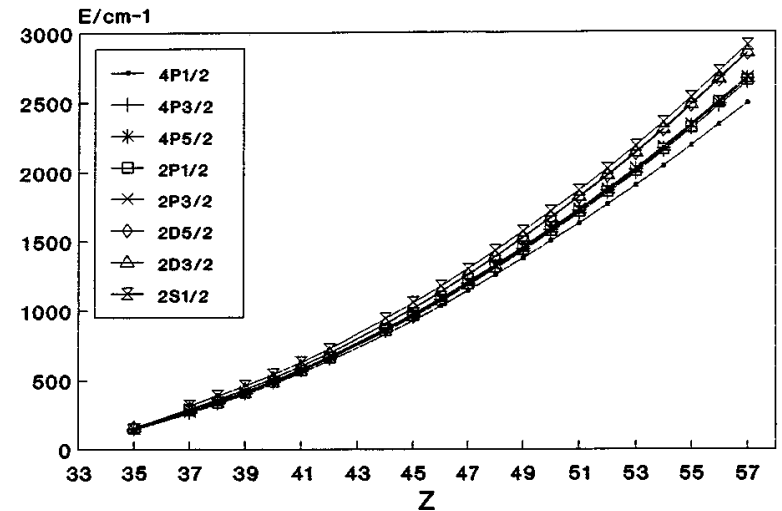

Fig. 3. MCDF energies for the levels of the excited configuration, $4 \mathrm{p}^{2} 5 \mathrm{~s}$, in As-like ions versus the atomic number

respectively, have been included in a few ions as a test. However, the final energies and oscillator strengths were practically unaffected by these inclusions whilst the computational time was appreciably increased. Therefore, the data we report in the Tables correspond to the inclusion of the specified configurations solely.

\section{Results and analysis}

The oscillator strengths for the different fine-structure transitions of the $4 \mathrm{p}^{3}-4 \mathrm{p}^{2} 5 \mathrm{~s}$ array of a number of As-like ions, object of the present study, are displayed in Tables 5 to 10 .

For each transition for which experimental energies were available, two RQDO sets of $f$-values are given, one obtained with the standard dipole-length transition operator, $Q(r)=r$, and the other with the core-polarization corrected transition operator, Eq. (1). The two sets of MCDF oscillator strengths correspond to calculations in the dipole-length and dipole-velocity forms, respectively. The MCDF $f$-values reported by O'Sullivan (1989) and O'Sullivan \& Maher (1989) up to Mo X have also been included for comparative purposes. In all the transitions, our MCDF calculations did not reach convergence both for Br III and Kr IV. For Rb V, all the theoretical as well as experimental $f$-values are anomalously low in magnitude. This feature is explained by O'Sullivan (1989) in terms of a large configuration mixing taking place in this particular ion that leads to a major distribution of intensity between $4 \mathrm{p}-5 \mathrm{~s}$ and $4 \mathrm{p}-4 \mathrm{~d}$ transitions. In all the studied transitions both our RQDO and MCDF $f$-values are in a general good accord with those reported by O'Sullivan (1989) and by O'Sullivan \& Maher (1989). As we go down in the sequence, a greater similarity between the dipole-length and dipole velocity MCDF oscillator strengths is observed. In most transitions, the effects of correcting the RQDO $f$ values for core polarization are sizable and bring them closer to the MCDF oscillator strenghts, in particular to those corresponding to the dipole-length calculation. 
Table 5. Oscillator strengths for the $4 \mathrm{p}^{3}{ }^{4} \mathrm{~S}_{3 / 2}^{\mathrm{o}}-4 \mathrm{p}^{2} 5 \mathrm{~s}{ }^{4} \mathrm{P}_{1 / 2}$ transition

\begin{tabular}{|lllcccc|}
\hline & & & & & \\
$Z$ & ION & RQDO $^{\mathrm{a}}$ & RQDO $^{\mathrm{b}}$ & $\mathrm{MCDF}^{\mathrm{c}}$ & $\mathrm{MCDF}^{\mathrm{d}}$ & MCDF $^{\mathrm{e}}$ \\
\hline & & & & & & \\
35 & Br III & 0.0710 & 0.0668 & - & - & 0.0663 \\
38 & Rb V & 0.0178 & 0.0183 & 0.0002 & 0.0005 & 0.0098 \\
39 & Y VI & 0.0572 & 0.0556 & 0.0392 & 0.0423 & $0.0585^{\mathrm{f}} / 0.0418$ \\
40 & Zr VIII & 0.0566 & 0.0552 & 0.0503 & 0.0514 & 0.0505 \\
41 & Nb IX & 0.0513 & 0.0508 & 0.0563 & 0.0567 & 0.0555 \\
42 & Mo X & 0.0646 & 0.0647 & 0.0610 & 0.0610 & 0.0598 \\
44 & Ru XII & & & 0.0652 & 0.0651 & 0.0640 \\
45 & Rh XIII & & & 0.0732 & 0.0731 & \\
46 & Pd XIV & & & 0.0771 & 0.0770 & \\
47 & Ag XV & & & 0.0808 & 0.0808 & \\
48 & Cd XVI & & & 0.0874 & 0.0843 & \\
49 & In XVII & & & 0.0902 & 0.0904 & \\
50 & Sn XVIII & & & 0.0928 & 0.0930 & \\
51 & Sb XIX & & & 0.0950 & 0.0953 & \\
52 & Te XX & & & 0.0971 & 0.0973 & \\
53 & I XXI & & & 0.0990 & 0.0992 & \\
54 & Xe XXII & & & 0.1007 & 0.1010 & \\
55 & Cs XXIII & & & 0.1022 & 0.1025 & \\
56 & Ba XXIV & & & 0.1037 & 0.1040 & \\
57 & La XXV & & & 0.1051 & 0.1054 & \\
\hline
\end{tabular}
a) Relativistic Quantum Defect Orbital Method, this work.
b) Relativistic Quantum Defect Orbital Method, with polarization, this work.
c) Multiconfigurational Dirac-Fock calculations, Babuskin gauge, this work.
d) Multiconfigurational Dirac-Fock calculations, Coulomb gauge, this work.
e) $f$-values reported by O'Sullivan (1989).
f) $f$-values reported by O'Sullivan \& Maher (1989).

An overall inspection of Tables 5 to 10 reveals that a sharp increase that occurs is most transitions at $\mathrm{Sr}$ VI, is apparent both in our calculations and experiment. O'Sullivan (1989) refers to it as an "array quenching" and explains it in terms of a sudden change in eigenvector composition of the $4 \mathrm{p}^{2} 5 \mathrm{~s}$ term.

In all the transitions for which we report both RQDO and MCDF $f$-values obtained in the present work, the largest discrepancies between the two sets of results occur in the first few ions of the sequence, for which the configuration mixing can be expected to be largest. Another possible reason for the discrepancies might be the fact that the LS coupling scheme has been adopted for all the ions in the RQDO procedure, unlike Biémont \& Hansen (1986) who adopted an intermediate coupling scheme in their calculations of magnetic dipole and electric quadrupole transitions in the ground state of the germanium and arsenic isoelectronic sequences.

\section{Concluding remarks}

RQDO and MCDF oscillator strenghs for the $4 \mathrm{p}^{3}-4 \mathrm{p}^{2} 5 \mathrm{~s}$ transition array of a number of As-like ions are presented.
When other MCDF data are available, our results are in good accord with them.

The RQDO procedure has once more proved to be a very useful tool for estimating transition probabilities. It is particularly adequate in the cases where mass-production of data is needed, given its cost-efficiency and reasonable accuracy. It offers also the advantage of its analiticity and lack of convergence problems from which elaborate ab initio calculations often suffer.

One drawback of the RQDO formalism is that it needs quantum defects from other sources as an input. But this can be, in many cases, circumvented by making use of the regularities presented by the quantum defects both along spectral series and isoelectronic sequences, which allow for inter- or extrapolations.

Acknowledgements. This work has been supported by the DGICYT of the Spanish Ministry of Education within Project No. PB94-1314-C03-03 and the J.C.L. within Project No. VA $21 / 97$. 
Table 6. Oscillator strengths for the $4 \mathrm{p}^{3}{ }^{4} \mathrm{~S}_{3 / 2}^{\mathrm{o}}-4 \mathrm{p}^{2} 5 \mathrm{~s}^{4} \mathrm{P}_{3 / 2}$ transition

\begin{tabular}{|c|c|c|c|c|c|}
\hline$Z \mathrm{ION}$ & $\mathrm{RQDO}^{\mathrm{a}}$ & $\mathrm{RQDO}^{\mathrm{b}}$ & $\mathrm{MCDF}^{\mathrm{c}}$ & $\mathrm{MCDF}^{\mathrm{d}}$ & $\mathrm{MCDF}^{\mathrm{e}}$ \\
\hline $35 \mathrm{Br}$ III & 0.1313 & 0.1242 & - & - & 0.1458 \\
\hline $37 \mathrm{Rb} \mathrm{V}$ & 0.0293 & 0.0307 & 0.0009 & 0.0013 & 0.0363 \\
\hline $38 \mathrm{Sr}$ VI & 0.0992 & 0.0977 & 0.0719 & 0.0771 & $0.106^{\mathrm{f}} / 0.0763$ \\
\hline 39 Y VII & 0.0975 & 0.0965 & 0.0853 & 0.0878 & 0.0875 \\
\hline $40 \mathrm{Zr}$ VIII & 0.0866 & 0.0870 & 0.0904 & 0.0917 & 0.0918 \\
\hline $41 \mathrm{Nb}$ IX & 0.0794 & 0.0808 & 0.0917 & 0.0926 & 0.0930 \\
\hline 42 Mo X & 0.0797 & 0.0812 & 0.0910 & 0.0915 & 0.0923 \\
\hline $44 \mathrm{Ru}$ XII & & & 0.0854 & 0.0860 & \\
\hline $45 \mathrm{Rh}$ XIII & & & 0.0815 & 0.0820 & \\
\hline 46 Pd XIV & & & 0.0771 & 0.0777 & \\
\hline $47 \mathrm{Ag} \mathrm{XV}$ & & & 0.0726 & 0.0732 & \\
\hline 48 Cd XVI & & & 0.0682 & 0.0688 & \\
\hline 49 In XVII & & & 0.0639 & 0.0647 & \\
\hline 50 Sn XVIII & & & 0.0601 & 0.0608 & \\
\hline $51 \mathrm{Sb}$ XIX & & & 0.0565 & 0.0573 & \\
\hline $52 \mathrm{Te}$ XX & & & 0.0533 & 0.0541 & \\
\hline 53 I XXI & & & 0.0505 & 0.0513 & \\
\hline 54 Xe XXII & & & 0.0480 & 0.0488 & \\
\hline 55 Cs XXIII & & & 0.0457 & 0.0465 & \\
\hline $56 \mathrm{Ba}$ XXIV & & & 0.0438 & 0.0445 & \\
\hline 57 La XXV & & & 0.0420 & 0.0428 & \\
\hline
\end{tabular}

See footnotes to Table 5 .

Table 7. Oscillator strengths for the $4 \mathrm{p}^{3}{ }^{4} \mathrm{~S}_{3 / 2}^{\mathrm{o}}-4 \mathrm{p}^{2}{ }_{5 \mathrm{~s}}{ }^{4} \mathrm{P}_{5 / 2}$ transition

\begin{tabular}{|c|c|c|c|c|c|}
\hline$Z \mathrm{ION}$ & $\mathrm{RQDO}^{\mathrm{a}}$ & $\mathrm{RQDO}^{\mathrm{b}}$ & $\mathrm{MCDF}^{\mathrm{c}}$ & $\mathrm{MCDF}^{\mathrm{d}}$ & $\mathrm{MCDF}^{\mathrm{e}}$ \\
\hline $35 \mathrm{Br}$ III & 0.2605 & 0.2433 & - & - & 0.2443 \\
\hline $37 \mathrm{Rb} \mathrm{V}$ & 0.0361 & 0.0385 & 0.0012 & 0.0014 & 0.0420 \\
\hline $38 \mathrm{Sr}$ VI & 0.1290 & 0.1285 & 0.0054 & 0.0041 & $0.148^{\mathrm{f}} / 0.1080$ \\
\hline 39 Y VII & 0.1279 & 0.1281 & 0.1173 & 0.1219 & 0.1205 \\
\hline $40 \mathrm{Zr}$ VIII & 0.1131 & 0.1152 & 0.1236 & 0.1268 & 0.1258 \\
\hline $41 \mathrm{Nb}$ IX & 0.1036 & 0.1070 & 0.1259 & 0.1283 & 0.1275 \\
\hline 42 Mo X & 0.1048 & 0.1081 & 0.1260 & 0.1281 & 0.1273 \\
\hline $44 \mathrm{Ru}$ XII & & & 0.1228 & 0.1248 & \\
\hline $45 \mathrm{Rh}$ XIII & & & 0.1204 & 0.1223 & \\
\hline 46 Pd XIV & & & 0.1176 & 0.1196 & \\
\hline $47 \mathrm{Ag} \mathrm{XV}$ & & & 0.1147 & 0.1168 & \\
\hline 48 Cd XVI & & & 0.1118 & 0.1139 & \\
\hline 49 In XVII & & & 0.1089 & 0.1111 & \\
\hline 50 Sn XVIII & & & 0.1062 & 0.1084 & \\
\hline $51 \mathrm{Sb}$ XIX & & & 0.1036 & 0.1059 & \\
\hline 52 Te XX & & & 0.1013 & 0.1036 & \\
\hline 53 I XXI & & & 0.0991 & 0.1014 & \\
\hline 54 Xe XXII & & & 0.0971 & 0.0994 & \\
\hline $55 \mathrm{Cs}$ XXIII & & & 0.0952 & 0.0976 & \\
\hline $56 \mathrm{Ba}$ XXIV & & & 0.0936 & 0.0959 & \\
\hline 57 La XXV & & & 0.0920 & 0.0943 & \\
\hline
\end{tabular}

See footnotes to Table 5.
Table 8. Oscillator strengths for the $4 \mathrm{p}^{3}{ }^{2} \mathrm{P}_{3 / 2}^{\mathrm{o}}-4 \mathrm{p}^{2} 5 \mathrm{~s}{ }^{2} \mathrm{~S}_{1 / 2}$ transition

\begin{tabular}{|lccccc|}
\hline$Z$ ION & RQDO $^{\mathrm{a}} \mathrm{RQDO}^{\mathrm{b}} \mathrm{MCDF}^{\mathrm{c}} \mathrm{MCDF}^{\mathrm{d}}$ & $\mathrm{MCDF}^{\mathrm{e}}$ \\
\hline $37 \mathrm{Rb}$ V & & & 0.0169 & 0.0245 & 0.0250 \\
$38 \mathrm{Sr}$ VI & & & 0.0369 & 0.0402 & $0.0601^{\mathrm{f}} / 0.0420$ \\
$39 \mathrm{Y}$ VII & 0.0439 & 0.0457 & 0.0453 & 0.0463 & 0.0485 \\
$40 \mathrm{Zr}$ VIII & 0.0449 & 0.0470 & 0.0493 & 0.0492 & 0.0513 \\
$41 \mathrm{Nb}$ IX & 0.0466 & 0.0489 & 0.0515 & 0.0508 & 0.0528 \\
$42 \mathrm{Mo}$ X & 0.0529 & 0.0548 & 0.0527 & 0.0517 & 0.0535 \\
$44 \mathrm{Ru}$ XII & & & 0.0540 & 0.0527 & \\
$45 \mathrm{Rh}$ XIII & & & 0.0544 & 0.0530 & \\
$46 \mathrm{Pd}$ XIV & & & 0.0546 & 0.0533 & \\
$47 \mathrm{Ag}$ XV & & & 0.0549 & 0.0535 & \\
$48 \mathrm{Cd}$ XVI & & & 0.0551 & 0.0537 & \\
$49 \mathrm{In}$ XVII & & & 0.0553 & 0.0539 & \\
$50 \mathrm{Sn}$ XVIII & & 0.0555 & 0.0541 & \\
\hline
\end{tabular}

See footnotes to Table 5 .

Table 9. Oscillator strengths for the $4 \mathrm{p}^{3}{ }^{2} \mathrm{P}_{1 / 2}^{\mathrm{o}}-4 \mathrm{p}^{2}{ }^{5 \mathrm{~s}}{ }^{2} \mathrm{~S}_{1 / 2}$ transition

\begin{tabular}{|c|c|c|c|c|c|}
\hline$Z \mathrm{ION}$ & $\mathrm{RQDO}^{\mathrm{a}}$ & $\mathrm{RQDO}^{\mathrm{b}}$ & $\mathrm{MCDF}^{\mathrm{C}}$ & $\mathrm{MCDF}^{\mathrm{d}}$ & $\mathrm{MCDF}^{\mathrm{e}}$ \\
\hline $37 \mathrm{Rb} \mathrm{V}$ & & & 0.0340 & 0.0457 & 0.046 \\
\hline $38 \mathrm{Sr}$ VI & & & 0.0581 & 0.0645 & 0.0655 \\
\hline 39 Y VII & 0.0651 & 0.0654 & 0.0696 & 0.0735 & $0.0868^{\mathrm{f}} / 0.0700$ \\
\hline $40 \mathrm{Zr}$ VIII & 0.0705 & 0.0708 & 0.0761 & 0.0788 & 0.0805 \\
\hline $41 \mathrm{Nb}$ IX & 0.0762 & 0.0763 & 0.0802 & 0.0823 & 0.0835 \\
\hline 42 Mo X & 0.0864 & 0.0859 & 0.0830 & 0.0847 & 0.0860 \\
\hline $44 \mathrm{Ru}$ XII & & & 0.0862 & 0.0876 & \\
\hline $45 \mathrm{Rh}$ XIII & & & 0.0870 & 0.0885 & \\
\hline $46 \mathrm{Pd}$ XIV & & & 0.0876 & 0.0890 & \\
\hline $47 \mathrm{Ag} \mathrm{XV}$ & & & 0.0879 & 0.0893 & \\
\hline 48 Cd XVI & & & 0.0879 & 0.0894 & \\
\hline 49 In XVII & & & 0.0879 & 0.0894 & \\
\hline 50 Sn XVIII & & & 0.0877 & 0.0893 & \\
\hline
\end{tabular}

See footnotes to Table 5 .

\section{References}

Bengston G.J., Berzinsh U., Larsson J., Svanverg S., 1992, A\&A 263,440

Bielińska-Wạz D., 1992, M. Sc. Thesis, University Nicholas Copernicus, Torun Poland

Biémont E., Hansen J.E., 1986, Phys. Scr. 33, 117

Bieroń J.R., Migdalek J., 1980, J. Phys. B: At. Mol. Opt. Phys. 25,4099

Charro E., Martín I., Lavín C., 1996, J. Quant. Spectrosc. Radiat. Transfer 56, 241; 1997, A\&AS 124, 1, and references therein

Chichkov B.N., Shevelko V.P., 1981, Phys. Scr. 23, 1055

Fraga S., Karwowski J., Saxena K.M.S., 1976, Handbook of Atomic Data. Elsevier, New York 
Table 10. Oscillator strengths for the $4 \mathrm{p}^{3}{ }^{2} \mathrm{D}_{3 / 2}^{\mathrm{o}}-4 \mathrm{p}^{2} 5 \mathrm{~s}^{2} \mathrm{P}_{3 / 2}$ transition

\begin{tabular}{|lccccc|}
\hline$Z$ ION & RQDO $^{\mathrm{a}}$ RQDO $^{\mathrm{b}}$ & $\mathrm{MCDF}^{\mathrm{c}}$ & $\mathrm{MCDF}^{\mathrm{d}}$ & $\mathrm{MCDF}^{\mathrm{e}}$ \\
\hline $35 \mathrm{Br}$ III & 0.0162 & 0.0158 & - & - & 0.00025 \\
$37 \mathrm{Rb} \mathrm{V}$ & & & 0.0104 & 0.0205 & 0.00 \\
38 Sr VI & & & 0.0183 & 0.0188 & 0.0120 \\
39 Y VII & 0.0298 & 0.0291 & 0.0233 & 0.0240 & 0.0188 \\
$40 \mathrm{Zr}$ VIII & 0.0288 & 0.0283 & 0.0281 & 0.0290 & 0.0248 \\
$41 \mathrm{Nb}$ IX & 0.0283 & 0.0280 & 0.0322 & 0.0331 & 0.0298 \\
$42 \mathrm{Mo}$ X & 0.0292 & 0.0293 & 0.0355 & 0.0364 & 0.0338 \\
$44 \mathrm{Ru}$ XII & & & 0.0392 & 0.0400 & \\
45 Rh XIII & & & 0.0400 & 0.0407 & \\
46 Pd XIV & & & 0.0402 & 0.0407 & \\
47 Ag XV & & & 0.0399 & 0.0404 & \\
48 Cd XVI & & & 0.0394 & 0.0398 & \\
49 In XVII & & & 0.0388 & 0.0391 & \\
50 Sn XVIII & & & 0.0380 & 0.0383 & \\
51 Sb XIX & & & 0.0373 & 0.0375 & \\
52 Te XX & & & 0.0366 & 0.0367 & \\
53 I XXI & & & 0.0360 & 0.0361 & \\
54 Xe XXII & & 0.0354 & 0.0355 & \\
55 Cs XXIII & & 0.0349 & 0.0349 & \\
\hline
\end{tabular}

See footnotes to Table 5 .
Grant I.P., in: Methods in Computational Chemistry, Vol. 2., 1988, Wilson S. (ed.). Plenum Press, New York, p. 1

Grant I.P., McKenzie B.J., Norrington P.H., Mayers D.F., Pyper N.C., 1980, Comput. Phys. Commun. 21, 207; Dyall K.G., Grant I.P., Johnson C.T., Parpia F.A., Plummer E.P., 1989, Comput. Phys. Commun. 55, 425

Kelly R.L., 1987, J. Chem. Ref. Data 16, Supp. 1

Leckrone D.S., Johansson S., Wahgren G.M., Proffitt C.R., Brage T., 1996, Phys. Scr. T65, 110

Martín I., Karwowski J., 1991, J. Phys. B: At. Mol. Opt. Phys. 24, 1538; Karwowski J., Martín I., 1991, Phys. Rev. A43, 4832

O'Sullivan G., 1989, J. Phys. B: At. Mol. Opt. Phys. 22, 978

O’Sullivan G., Maher M., 1989, J. Phys. B: At. Mol. Opt. Phys. 22,377

Rahimullah K., Chagtai M.S.Z., Khatoon S., 1976, Phys. Scr. 14, 221; 1978, Phys. Scr. 18, 96

Reader J., Acquista N., 1981, J. Opt. Soc. Am. 71, 434

Simons G., 1974, J. Chem. Phys. 60, 645; Martín I., Simons G., 1975, J. Chem. Phys. 62, 4799; 1976, Mol. Phys. 32, 1017 